\title{
Identifying Argumentative Patterns: A Vital Step in the Development of Pragma-Dialectics
}

\author{
Frans H. van Eemeren ${ }^{1,2,3}$
}

Published online: 23 September 2015

(C) The Author(s) 2015. This article is published with open access at Springerlink.com

\begin{abstract}
This paper serves as an introduction to the special issue on argumentative patterns in discourse, more in particular on argumentative patterns with pragmatic argumentation as a main argument that are prototypical of argumentative discourse in certain communicative activity types in the political, the legal, the medical, and the academic domain. It situates the studies of argumentative patterns reported in these papers in the pragma-dialectical research program. In order to be able to do so, it is first explained in which consecutive stages the pragma-dialectical theorizing has developed, what the study of argumentative patterns involves, and why the identification of argumentative patterns represents a vital stage in the development of pragma-dialectics. The description of the theoretical innovations that are introduced and the exposition of their relationship with the standard and extended pragma-dialectical theory create a conceptual and terminological framework for understanding the background and the rationale of the current research projects.
\end{abstract}

Keywords Argumentative characterization - Argumentative pattern · Extended pragma-dialectics · Institutional precondition · Pragmatic argumentation · Prototypical argumentative pattern - Standard pragma-dialectics · Stereotypical argumentative pattern $\cdot$ Strategic manoeuvring

Frans H. van Eemeren

f.h.vaneemeren@uva.nl

1 University of Amsterdam, Groenburgwal 53, 1011 HS Amsterdam, The Netherlands

2 Leiden University, Leiden, The Netherlands

3 ILIAS, Amsterdam, The Netherlands 


\section{Introduction}

When I started, together with Grootendorst, developing the pragma-dialectical theory of argumentation in the 1970s, our primary interest was to develop adequate tools for enhancing the quality of the ways in which people justify their views and analyse and critically review the justifications of views they encounter. A methodical reflection on the conduct of argumentative discourse seemed therefore crucial to us. Our master plan for developing our theoretical approach involved progressing step by step from designing an abstract model of normatively ideal argumentative discourse to dealing with the intricacies of the broad variety of argumentative practices constituting argumentative reality. Starting from the basics, we planned to flesh out the pragma-dialectical theory in such a way that gradually more and more properties of actual argumentative discourse would be taken into account.

Characteristically, in the pragma-dialectical approach, argumentation is studied both from a communicative perspective, inspired by pragmatic insights from ordinary language philosophy, speech act theory and discourse analysis, and from a critical perspective, inspired by dialectical insights from critical rationalism and dialogue logic (van Eemeren and Grootendorst 1984, 2004). By carrying out a research program integrating descriptive and normative insights, in the pragmadialectical theory a commitment to empirically adequate description is methodically linked with a critical stance towards argumentative practices (van Eemeren 1987). As a consequence, the pragma-dialectical approach of argumentation differs considerably not only from formal and informal logical approaches concentrating primarily on the normative treatment of reasoning problems, but also from the primarily descriptive and explanatory approaches of argumentative discourse favoured in communication studies, rhetoric and linguistics. ${ }^{1}$

This paper serves as an introduction to the special issue of Argumentation on prototypical argumentative patterns in argumentative discourse. It explains that the identification of argumentative patterns represents a vital stage in the development of the theoretical framework of pragma-dialectics and situates the studies of argumentative patterns reported in the various papers in the pragma-dialectical research program. I will describe how, starting from an ideal model for conducting a critical discussion, the theorizing has been systematically brought closer to the complexities of situated argumentative discourse in actual argumentative practices. Section 2 is devoted to the "standard" pragma-dialectical theory, consisting of the model and the rules for critical discussion, on which all further developments are based. In Sect. 3, analytical and empirical research aimed at consolidating the standard theory is discussed. Section 4 throws light on the "extended" pragmadialectical theory based on the introduction of the notion of strategic maneuvering, which adds a rhetorical dimension to the theory. Section 5 introduces the experimental research of effectiveness-through-reasonableness connected with the

\footnotetext{
1 The meta-theoretical starting points of pragma-dialectics, which serve as its methodological premises, can in fact be seen as constructive responses to what we considered to be shortcomings of other approaches (van Eemeren \& Grootendorst, 1984, pp. 4-18; van Eemeren et al. 2014, pp. 523-527).
} 
extended pragma-dialectical theory. Section 6 makes clear how including strategic maneuvering in the treatment of argumentative discourse has led to taking account of the institutionally conventionalized contexts in which the discourse takes place. Section 7 is devoted to the institutional preconditions for strategic maneuvering associated with such conventionalized contexts. Section 8 discusses the prototypical argumentative patterns resulting from taking the institutional preconditions into account in conducting argumentative discourse in specific communicative activity types. Section 9 focuses on the topic of this special issue, argumentative patterns with pragmatic argumentation as main argument. Section 10, finally, introduces the various contributions to this issue concentrating on prototypical argumentative patterns containing argumentation in the political, the legal, the medical and the academic domain.

\section{The Pragma-Dialectical Standard Theory}

In order to clarify what is involved in viewing argumentative discourse as aimed at resolving a difference of opinion on the merits, we developed an ideal model of a critical discussion (van Eemeren and Grootendorst 1984; van Eemeren et al. 2014, pp. 527-533). In a critical discussion the parties attempt to reach agreement about the acceptability of the standpoint at issue by finding out whether or not this standpoint is tenable against critical doubt and other criticism in view of certain mutually accepted starting points. ${ }^{2}$ In the model of a critical discussion we specified the four stages that are to be distinguished in the resolution process and the speech acts constituting the argumentative moves instrumental in each of these stages.

In the pragma-dialectical theory we have depicted the standards of reasonableness applying to argumentative discourse as rules for critical discussion (van Eemeren and Grootendorst 2004, pp. 135-157). Together, the rules for critical discussion constitute a dialectical procedure for the performance of speech acts. To resolve a difference of opinion on the merits, the speech acts performed by the protagonist and the antagonist of the standpoint at issue must comply in each stage with all the rules. Any violation of any of the rules by any of the parties at any stage of the discussion frustrates or hinders the process of resolving a difference of opinion on the merits. Every argumentative move in which this happens we therefore consider a "fallacy". 3

The pragma-dialectical model of a critical discussion serves heuristic and analytic functions in dealing with interpretation problems that may arise in analysing argumentative discourse. It indicates what to look for in reconstructing argumentative discourse from a resolution-minded perspective and in what way the

\footnotetext{
2 A critical discussion reflects the Socratic dialectical ideal of testing any form of conviction rationally, not only descriptive statements but also value judgments and practical standpoints about actions.

3 The instrumentality of the rules for critical discussion in distinguishing counterproductive moves demonstrates their "problem-validity" as a code of conduct (van Eemeren and Grootendorst 1994). In order to serve in practice as tools for resolving differences of opinion on the merits, the rules also need to be "conventionally valid". van Eemeren et al. (2009) have shown that these standards of reasonableness are to a large extent intersubjectively accepted and can therefore lay claim to conventional validity.
} 
discourse can be most appropriately analysed from this perspective. The model also serves a critical function by providing, through the rules for critical discussion, a coherent set of norms for determining in which respects an argumentative move deviates from the course that is conducive to resolving a difference of opinion on the merits. Due to its heuristic, analytic and critical functions, the pragma-dialectical model of a critical discussion constitutes an adequate basis for developing practical guidelines for the conduct, analysis and evaluation of argumentative discourse.

\section{Consolidation of the Standard Theory}

More often than not, in argumentative discourse certain indispensable components of the resolution process are left unexpressed because they are considered clear or self-evident - and sometimes for less honorable reasons. Constitutive parts of the difference of opinion, the procedural and material starting points, the relations between different arguments put forward in defense of a standpoint, and the way in which individual arguments are supposed to support the standpoint at issue may not have been explicitly articulated. In particular in argumentative discourse that is a monologue some crucial ingredients of the resolution process remain concealed. In all these cases, the missing elements need to be recovered through a reconstructive analysis.

The model of a critical discussion is a heuristic and analytic tool in reconstructing argumentative discourse by serving as a "template" that constitutes a point of reference and ensures that the discourse can be reconstructed in terms of argumentative moves relevant to resolving a difference of opinion on the merits. Based on the pragma-dialectical standard theory, in the reconstruction process various kinds of "reconstruction transformations" can be carried out (van Eemeren 1986). The reconstruction is to result in an "analytic overview" that highlights those, and only those, elements in the discourse that are pertinent to a well-balanced critical evaluation.

In pragma-dialectics the required analytical tools needed to be developed to enable analysts to achieve an adequate analytic overview. Among the tools developed are a method for making unexpressed premises explicit and typologies of argument schemes and argumentation structures that can be used to identify the relationships between argumentative moves (van Eemeren and Grootendorst 1992). Fundamental pragma-dialectical instruments for exploiting these tools are the socalled rules of communication (van Eemeren and Grootendorst 1992, pp. 49-52). The rules of communication are based on an integration of an amended version of Searle's felicity conditions for the performance of speech acts in communication and an amended version of the Gricean maxims for the conduct of verbal interaction. When a rule of communication seems to be violated while the "general principles" of communication and interaction may be assumed not to be abandoned, the analyst is to make an effort-just like ordinary listeners and readers do- to reconstruct the implicit and indirect speech act involved in such a way that the violation is remedied and the reconstructed speech act agrees with the rules of communication (van Eemeren and Grootendorst 1992, pp. 52-59). This analytic 
policy also applies to the reconstruction of unexpressed premises (van Eemeren and Grootendorst 1992, pp. 60-72).

In order to investigate the connections of pragma-dialectics with argumentative reality, empirical research is required. The "qualitative" empirical research we have carried out has focused primarily on the way in which argumentative moves relevant to a critical discussion manifest themselves in argumentative reality (van Eemeren et al. 1993). In the Indicator Project, we systematically examined the clues for reconstructing argumentative moves by means of qualitative empirical research (van Eemeren et al. 2007). Our central goals were to identify the words and expressions that arguers use to indicate the functions of the various moves they make, to classify these moves in accordance with the argumentative functions they can have in the various stages of the resolution process, and to determine under which conditions they fulfil these functions. In examining systematically the ways in which argumentative moves are realized in argumentative reality we took as our point of departure the notion of "dialectical profiles", introduced by van Eemeren and Houtlosser (2007). Dialectical profiles specify the kinds of moves that can be instrumental in realizing the specific tasks of the discussants at a particular point in the discussion and the "dialectical routes" in which these moves are included. The dialectical routes are specifications of the series of "analytically relevant" moves that can be made in the argumentative exchange that is portrayed.

To establish the necessary connection between the pragma-dialectical theory and argumentative reality, since the mid-1980s we have also been engaged in quantitative empirical research of an experimental nature. Initially this research concentrated on the extent to which in argumentative reality the recognition of argumentative moves is facilitated or hampered by factors in the presentation (e.g., van Eemeren et al. 1984, 1989, 2000). Next, the clues for the recognition of indirect argumentation provided by the context were taken into account.

In order to determine the "intersubjective validity" of the pragma-dialectical standards for critical discussion, in a comprehensive research project, Conceptions of Reasonableness, we concentrated for more than 10 years on ordinary arguers' assessments of argumentative moves. This resulted in the monograph Fallacies and Judgments of Reasonableness (van Eemeren et al. 2009). The general aim of the project was to check to what extent ordinary arguers judge the reasonableness of argumentative moves according to norms that match the norms expressed in the rules for critical discussion. The general conclusions that can be deduced from the research results are that the pragma-dialectical discussion rules are intersubjectively valid to quite a high degree and that there are no spectacular differences in degree of intersubjective validity between the rules (van Eemeren et al. 2009, pp. 222-224). Based on this indirect evidence, the rules may therefore lay claim to conventionally validity, both individually and as a group. 


\section{The Extended Pragma-Dialectical Theory}

After the standard theory had thus been consolidated, the pragma-dialectical research has moved on from the ideal model of a critical discussion to the concrete manifestations of the manifold practices of argumentative discourse. At the end of the twentieth century, I set about, together with Houtlosser, to strengthen the connection with argumentative reality in a fundamental way by including an account of the "strategic design" of argumentative discourse in the theorizing (van Eemeren 2010). The aim of including this vital but unexplored facet of argumentative discourse in the theorizing was to extend the available analytic and evaluative tools in such a way that more profound reconstructions and more realistic assessments of argumentative discourse can be given, which can at the same time be accounted for more thoroughly. ${ }^{4}$

Considering that for explaining the strategic design of argumentative discourse, next to the dialectical dimension of reasonableness predominant in the standard theory, the rhetorical dimension of effectiveness needed to be incorporated in the theorizing, we started in the 1990s the Strategic Maneuvering Project (van Eemeren and Houtlosser 2002). Our starting point was the "argumentative predicament" of real-life argumentative discourse that, in every argumentative move that is made, aiming for effectiveness and maintaining reasonableness always need to go together. Because of the tension inherent in pursuing simultaneously these two objectives, "strategic maneuvering" is required to keep the balance. In case arguers in their pursuit of effectiveness neglect their commitment to reasonableness and violate one or more of the rules for critical discussion, their strategic maneuvering "derails" into fallaciousness (van Eemeren 2010, p. 198).

Adopting the theoretical notion of strategic maneuvering involves adding a rhetorical dimension to the theoretical framework of pragma-dialectics. It is our considered opinion that the dialectical and the rhetorical perspectives on argumentative discourse are not incompatible, and can even be complementary (van Eemeren 2013). In our view, studying the pursuit of rhetorical effectiveness in argumentative discourse is in fact only worthwhile if it concerns effectiveness reached within the boundaries of dialectical reasonableness, while setting dialectical standards of reasonableness in argumentation theory is only of any practical significance if it is combined with examining how rhetorical tools for achieving effectiveness are brought to bear. This is why we think that the future of argumentation theory lies in a constructive integration of the dialectical and the rhetorical perspectives (van Eemeren 2010, pp. 87-92). In bringing about such an integration in pragma-dialectics, the notion of strategic maneuvering is the primary theoretical tool. ${ }^{5}$

\footnotetext{
${ }^{4}$ Including an account of the strategic design in the theorizing is also helpful in developing more sophisticated methods for improving the conduct of argumentative discourse, both orally and in writing.

5 Albeit in different ways, the rapprochement between dialectical and rhetorical approaches to argumentation is also stimulated by communication scholars such as Wenzel (1990) and informal logicians such as Tindale (2004).
} 


\section{Empirical Research of Effectiveness Through Reasonableness}

The introduction of the theoretical notion of strategic maneuvering in the extended pragma-dialectical theory of argumentation has opened up new venues for empirical research. In 2010, we have started a comprehensive research project, Hidden Fallaciousness. In this project we carry out a series of experiments concerning the relationship between the arguers' aiming for rhetorical effectiveness and their complying with dialectical standards of reasonableness. In these experiments we they start from three theoretically-motivated hypotheses which are strongly supported by pertinent empirical data (van Eemeren et al. 2012a). ${ }^{6}$

First, since they generally prove to know which contributions to a discussion are to be considered reasonable and which contributions unreasonable, ordinary arguers are to a certain extent aware of what their dialectical obligations involve. If they were not aware of any such standards of reasonableness, there could not be a rational relationship in their strategic maneuvering between aiming for effectiveness and maintaining reasonableness. The fact that, in practice, they commit themselves to standards of reasonableness equivalent with the pragma-dialectical standards (van Eemeren et al. 2009, p. 206) makes it possible to substantiate more precisely what reasonableness means to them.

Second, ordinary arguers assume that, in principle, the other party in the discussion will be committed to the same kind of dialectical obligations as they are. If they did not start from this assumption, it would be pointless for them to appeal to the other party's standards of reasonableness by putting forward argumentation to justify their standpoints in order to resolve the difference of opinion between them and the other party. The fact that they assume that there are shared standards of reasonableness makes it possible to connect their standards of reasonableness with their aiming for effectiveness vis-à-vis the other party.

Third, ordinary arguers prefer-and assume their interlocutors to prefer-that contributions to the discussion that do not comply with supposedly shared standards for critical discussion will be regarded as unreasonable and that those who offend these standards can be held accountable for being unreasonable. If they did not wish the prevailing standards to be put into effect, their argumentative efforts would be pointless. The fact that arguers turn out to give a prescriptive meaning to reasonableness when taking part in argumentative practices, and expect their interlocutors to do the same, makes it possible to interpret the connection between reasonableness and effectiveness in such a way that reasonableness may, in principle, be expected to lead to effectiveness-even if in some cases reasonableness would not be the only factor (and not necessarily the most influential factor) that brings about effectiveness. Correlatively, if reasonableness is lacking or deficient, effectiveness may be expected to suffer.

Against the background of these considerations, we concluded that it makes sense for argumentation theorists to examine the relationship between

\footnotetext{
6 The three hypotheses are closely connected with the theoretical views on the relationship between reasonable argumentation and effectiveness in the sense of convincingness expounded in van Eemeren and Grootendorst (1984).
} 
reasonableness and effectiveness empirically. In this empirical research, we defined "effectiveness" of an argumentative move as realizing the "inherent" interactional (perlocutionary) effect that is conventionally associated with performing the speech act by which that argumentative move is made (van Eemeren and Grootendorst 1984, pp. 24-29). In order to serve its purposes optimally, pragma-dialectical effectiveness research concentrates on the pursuit of intentional effects of strategic maneuvering on the state of the addressee's dialectical commitments that are, or can be, externalized. ${ }^{7}$ It focuses in the first place on effects achieved by reasonable means which are based on an adequate understanding of the functional rationale of the argumentative moves and depend on rational considerations on the part of the addressee. ${ }^{8}$ Steering the research in this way agrees with the pragma-dialectical view of reasonableness as a necessary condition for convincingness - the rational version of persuasiveness (van Eemeren and Grootendorst 1984, p. 48).

In light of the finding that discussion moves that are from our theoretical perspective fallacious are also judged unreasonable by ordinary language users, it might seem remarkable that when such moves occur in argumentative discourse the fallacies appear many times not to be noticed by the participants. A striking example of a fallacy that is easily overlooked is the "abusive variant" of the argumentum ad hominem. When rating the reasonableness of clear cases of this fallacy in an experimental situation ordinary arguers overwhelmingly judge it to be a very unreasonable discussion move (van Eemeren et al. 2009, p. 206). Nevertheless, in real life argumentative discourse this fallacy remains in a great many cases undetected. Such striking discrepancies need to be explained.

In "The disguised abusive ad hominem empirically investigated", we have argued that in certain cases the abusive ad hominem can be analyzed as a mode of strategic maneuvering in which this fallacy takes on a reasonable appearance because it mimics legitimate critical reactions to authority argumentation (van Eemeren et al. 2012b). When co-arguers present themselves wrongfully as experts in a certain field, or claim to be trustworthy when in fact they are not, attacking them personally about that is a perfectly legitimate and reasonable move. As a consequence of the fact that there happen to be special cases like these, it may not always be immediately clear whether a personal attack must be seen as reasonable critique or as a fallacious ad hominem move. In two experiments we have systematically tested the hypothesis that abusive ad hominem attacks are seen as substantially less unreasonable by ordinary arguers when these attacks are presented as if they are critical reactions to authority argumentation in which the

\footnotetext{
7 This type of effectiveness research constitutes the critically inspired pragma-dialectical complement to the prevailing (non-dialectical) persuasion research. Our preference for the label "effectiveness research" rather than "persuasiveness research" is motivated by the fact that, unlike the term persuasiveness, the term effectiveness is not exclusively connected with the argumentation stage but also pertains to argumentative moves made in other discussion stages (e.g. proposing starting points, stating the outcome of the discussion).

8 See the analysis of "interactional" (perlocutionary) effects in van Eemeren and Grootendorst (1984, pp. 63-74) and van Eemeren (2010, pp. 36-39).
} 
person attacked wrongly parades as an authority. In both experiments the hypothesis was confirmed. ${ }^{9}$

\section{Taking the Institutional Context of Argumentative Discourse into Account}

Because strategic maneuvering does not take part in an idealized critical discussion but in the multi-varied communicative practices that have developed in argumentative reality, in the extended pragma-dialectical theory due account needs to be given of the macro-context of the institutional environment in which the argumentative discourse takes place. We do so by relating our treatment of strategic maneuvering in argumentative discourse immediately to the "communicative activity types" that have established themselves in the various communicative domains in response to the institutional exigencies of the domain. These communicative activity types have been conventionalized in accordance with the needs of the institutional macro-context (van Eemeren 2010, pp. 129-162). ${ }^{10}$

It is through the use of the appropriate "genres" of communicative activity, ${ }^{11}$ varying from adjudication in the legal domain and deliberation in the political domain to disputation in the academic domain, that communicative activity types are designed to serve their rationale: the "institutional point" reflecting the exigency in response to which the activity type has come into being. The institutional point of a parliamentary debate, for instance, is reaching a well-considered decision on a policy proposal. To complicate matters, in realizing the institutional point of "hybrid" communicative activity types several genres of conventionalized communicative activity are activated together. In a political interview, for instance, deliberation is intrinsically combined with disseminating information to realize the institutional point of enlightening the audience or readership (van Eemeren to be published).

The way in which communicative activity types are conventionalized to make their institutional point can be explicit and highly formalised in constitutive and regulative rules, as is usual in adjudication in the legal domain. The conventionalization may also be partly implicit and formalised to a lesser degree in looser regulations of some kind, as is often the case in deliberation in the political domain. The conventionalization might even be only informal and simply reflect established practices, as is customary in communion-seeking in the interpersonal domain.

The next step we had to take in our research program was to explore the consequences engaging in a particular communicative type has for the conduct of

\footnotetext{
${ }^{9}$ Both in the original test and in the replication straightforward abusive attacks are consistently rejected as unreasonable discussion moves and legitimate personal attacks are invariably considered reasonable. The "disguised" abusive attacks presented as responses to a wrong use of authority however are judged as substantially less unreasonable than the overtly fallacious direct attacks.

${ }^{10}$ Communicative activity types are in pragma-dialectics defined as communicative practices whose conventionalization serves the specific communicative needs instigated by the institutional exigencies of a certain domain (van Eemeren 2010, pp. 139-145).

11 Fairclough characterizes a "genre" of communicative activity broadly as "a socially ratified way of using language in connection with a particular type of social activity" (1995, p. 14).
} 
argumentative discourse (van Eemeren 2010, pp. 144-159). The ideal model of a critical discussion can be instrumental in characterizing the particular ways in which, depending on the specific institutional requirements that must be fulfilled, the argumentative dimension is substantiated in the various communicative activity types. Using the model of a critical discussion in all cases as the analytical point of reference not only ensures a coherent and consistent appreciation of the argumentative dimension, but it also creates unity in the comparison between different communicative activity types. ${ }^{12}$

Taking the four stages of a critical discussion as the point of departure, four focal points can be identified that need to be taken into account in an argumentative characterization of a specific communicative activity type (van Eemeren 2010, p. 146). ${ }^{13}$ These four focal points are the empirical counterparts of the four stages of the process of resolving a difference of opinion in contextualized argumentative discourse: the initial situation (confrontation stage), the starting points (opening stage), the argumentative means and criticisms (argumentation stage), and the outcome of the exchange (concluding stage). Starting from this division helps us to determine in the argumentative characterization in what way exactly the constitutive stages of the process of resolving a difference of opinion on the merits are represented in a certain communicative activity type.

Because communicative activity types impose certain extrinsic constraints on the possibilities for strategic maneuvering, it is necessary to take the conventionalization of the communicative activity type in which the argumentative discourse takes place into account when analyzing and evaluating strategic maneuvering. Together, the institutional point and the conventionalization determine the "institutional preconditions" for strategic maneuvering in a particular communicative activity type. In pragma-dialectics we distinguish between "primary" institutional preconditions, which are as a rule official, usually formal, and often procedural, and "secondary" institutional preconditions, which are as a rule unofficial, usually informal, and often substantial (van Eemeren and Garssen 2010, 2011).

As is indicated by the conventionalization determining the institutional preconditions, in a particular communicative activity type certain modes of strategic maneuvering will be suitable-or not suitable, as the case may be-to realizing the institutional point of the activity type. Since an argumentative characterization of the communicative activity type makes clear in what way exactly the argumentative discourse is conventionalized to serve the institutional point of the activity type, this characterization provides an appropriate point of departure for tracing methodically the ways in which the possibilities for strategic maneuvering are in practice affected by the communicative activity type.

From communicative activity type to communicative activity type the scope of the possibilities available for strategic maneuvering in each of the empirical counterparts of the critical discussion stages may vary. In some communicative

\footnotetext{
${ }^{12}$ Diversity is then not the relativistic point of departure, but a reality-based outcome of a systematic comparison of the various manifestations of argumentative reality.

13 An argumentative characterization of a communicative activity type is only worthwhile when it is inherently, essentially or predominantly argumentative or argumentation incidentally plays an important part.
} 
activity types, for instance, the participants will be allowed more room for defining the initial situation in accordance with their own preferences than in others. A similar variety may exist with regard to the choice of procedural and material starting points, the choice of argumentative means and kinds of criticism, and the outcomes of the argumentative exchange. In each particular case, all three aspects of strategic maneuvering can be affected by the need to comply with the institutional preconditions (van Eemeren 2010, pp. 93-127). There may be constraints on the topical choices that are allowed, on the adaptation to audience demand that is regarded appropriate, and on the presentational devices that are permitted. Although these constraints are in principle a limitation of the possibilities for strategic maneuvering, they may also create special opportunities for strategic maneuvering to some of the participants.

\section{Institutional Preconditions for Strategic Maneuvering}

After having included strategic maneuvering in extended pragma-dialectics we further strengthened the connection between the theory and argumentative reality by incorporating the contextual dimension of the communicative activity types in the theorizing. In examining argumentative practices we concentrate on four domains: (1) the legal domain, often seen as the proving ground for theorizing about argumentation and since the 1980s a focal point of pragma-dialectical research; (2) the political domain, vital for the use of argumentation in public life and central to stimulating laymen's interest in argumentation theory; (3) the medical domain, moving on from paternalistic decision-making by doctors to informed consent based on argumentation; and (4) the academic domain, viewed as the pinnacle of certainty by outsiders but in fact pervaded by argumentation. Our general research aims are in all cases: (1) to identify the institutional preconditions constraining the possibilities for strategic maneuvering in specific communicative activity types; (2) to identify the prototypical argumentative patterns resulting from realizing the institutional point of specific communicative activity types in accordance with the institutional preconditions.

Characteristically, in the legal domain the communicative practices have been strongly conventionalized. In a law case, the procedural and material starting points defining the legal counterpart of the opening stage of a critical discussion are generally to a large extent predetermined institutionally rather than determined by the parties in mutual deliberation. To identify the institutional preconditions for strategic maneuvering in communicative activity types in the legal domain, pragmadialecticians examine how these activity types can be characterized argumentatively. Next they try to establish how, in the various kinds of legal practices, the parties involved, including the judge, operate in conducting their argumentative discourse and what room for strategic maneuvering they have (Feteris 2009).

Pragma-dialectical research concerning the political domain was initiated by a discussion of the role of argumentation in democracy (van Eemeren 2002). A comprehensive research project examining the influence of institutional preconditions on confrontational strategic maneuvering was carried out by van Eemeren, Houtlosser, van Laar, and some PhD researchers. Andone (2013), for one, set out to 
provide an argumentative explanation of the way in which politicians react in political interviews to the interviewer's accusation that they have taken on a standpoint which is inconsistent with a standpoint they advanced earlier. Mohammed (2009) examined the Prime Minister's responses to critical questions by members of the opposition in Prime Minister's Question Time in the British House of Commons. Tonnard (2011) gave an account of presentational tactics used by politicians in their strategic maneuvering to get the priority issues of their party discussed in Dutch parliament when they are not on the agenda. In a related project, focusing on the contextual conditions of political discussion forums on the Internet affecting the way in which the participants react critically, Lewinski (2010) examined how on-line technologies create new possibilities for public debate.

Meanwhile, van Eemeren and Garssen had started in 2009 a comprehensive research project examining the institutional preconditions for strategic maneuvering in argumentative exchanges in the European Parliament. So far, their research has concentrated in the first place on the impact of "the European predicament". The European predicament is a secondary institutional precondition involving the extrinsic constraint silently imposed upon Members of the European Parliament that they are supposed to serve at the same time the European cause and to satisfy their electorate by protecting the national interests of their home countries (van Eemeren and Garssen 2010, 2011). ${ }^{14}$

In the medical domain, pragma-dialecticians examine the strategic maneuvering that is needed to comply with institutional preconditions in health communication (Snoeck Henkemans 2011). In medical consultations, for instance, doctors are under the obligation to make clear to their patients that their judgments and advices are sound, but doctor and patient differ as a rule considerably in medical knowledge and experience. Doctors need to take this institutional precondition into account in their strategic maneuvering, for instance, when they decide bringing their own authority to bear (Labrie 2012; Pilgram 2015). The relationship between strategic maneuvering and institutional preconditions has also been examined in advertisements promoting medical drugs (Wierda 2015) and in health brochures promoting the target audience to eat less, exercise more, have safe sex, etc. (van Eemeren 2013; van Poppel 2013).

Pragma-dialectical research concerning the institutional preconditions an academic context imposes on the strategic maneuvering is still in its infancy. A first effort to adapt the theoretical instruments of pragma-dialectics for implementation in this type of communicative activity types is made by Wagemans (2011) with regard to the reconstruction and evaluation of argumentation from expert opinion.

\section{Prototypical Argumentative Patterns}

The initial situation in the communicative activity types that have come into being in the various communicative domains revolves around different kinds of differences of opinion. The types of standpoints at issue vary from evaluative and

\footnotetext{
14 Still other pragma-dialectical research projects focus on argumentative discourse in Dutch Parliament (Plug 2010, 2011) and the use of pragmatic argumentation in lawmaking debates in British Parliament (Ihnen Jory 2010, 2012).
} 
prescriptive standpoints to descriptive standpoints, while there are also hybrid standpoints in which descriptive, evaluative and prescriptive elements go together. In combination with the specific starting points that are characteristic of a particular communicative activity type or cluster of communicative activity types, the specific characteristics of the initial situation will lead to specific kinds of argumentative exchanges in the empirical counterpart of the argumentation stage and to specific kinds of outcome of the discussion.

The differences between the kinds of argumentative exchanges that develop or are likely to develop in the various kinds of communicative activity types are not only caused by differences between the kind of difference of opinion (varying from a formally defined mixed dispute in a law case to an informal non-mixed difference in a medical consult), the types of standpoints at issue (varying from a prescriptive standpoint in a parliamentary policy debate to a descriptive standpoint in a scientific discussion), and the procedural and material starting points (varying from explicitly established starting points in a law case to largely implicit starting points in a personal chat), but also by the specific requirements pertaining to the way in which the exchange between argumentation and criticism is to take place (varying from strongly regulated exchanges in a parliamentary debate to exchanges largely determined by the participants in a private discussion) and the kinds of outcome that are to be reached (varying from a final verdict of the judge in a law case to a change of mind of one of the parties or the maintenance of the initial situation in a private discussion).

In view of the kind of difference of opinion to be resolved, the type of standpoint at issue and the specific procedural and material starting points the parties must act upon in the communicative activity types concerned, different types of argumentation can be helpful in reaching the kind of outcome that is aimed for. In the communicative activity types associated with specific communicative domains certain types of argument schemes will be pre-eminently instrumental in reaching the desired kind of outcome. Depending on the critical questions pertaining to the (sub)type(s) of argument scheme(s) employed in the main argument(s) in support of the standpoint at issue, ${ }^{15}$ in the particular shape these critical questions take in the communicative activity type at hand, ${ }^{16}$ specific kinds of critical reactions need to be anticipated or responded to in the argumentative exchanges that take place. ${ }^{17}$

In the legal domain, in an argumentative exchange taking place in the communicative activity type of a law case, characteristically, "symptomatic" argumentation supported by "analogy" argumentation may be used to legitimize a

\footnotetext{
15 In the subtypes of the argument schemes used in the various subtypes of a certain type of argumentation the critical questions pertaining to that scheme will be specified in somewhat different ways.

16 The relevant critical questions need to be envisaged in the implementation pertinent to the use of the argument scheme concerned in the specific macro-context of the communicative activity type.

17 It depends on the micro-, meso-, macro- and intertextual context, the logical and pragmatic inferences that can be drawn and the available general and specific background information (van Eemeren 2010, pp. 17-19), which particular critical questions are by institutional convention required to be answered in a certain communicative activity type.
} 
legal verdict. ${ }^{18}$ This means that in such a case the specific types of critical questions are pertinent that are associated with symptomatic argumentation and analogy argumentation. In the political domain, in an argumentative exchange taking place in the communicative activity type of a parliamentary debate, the use of "pragmatic" argumentation is a characteristic way to defend a policy standpoint, and the pertinent critical questions can be specified accordingly. ${ }^{19}$ In the academic domain, in an argumentative exchange taking place in the communicative activity type of a scientific discussion, using certain subtypes of "causal" argumentation is a characteristic way to establish the truth of a scientific claim, and the pertinent critical questions are those associated with the particular (sub)type of causal argumentation that is used. ${ }^{20}$

In conducting an argumentative exchange, the arguers are supposed to take the institutional preconditions of the communicative type and the critical reactions into account that are pertinent in the communicative activity type concerned when a certain argument scheme is being used. Doing so will result in the creation of what I have named a specific argumentative pattern in the discourse (van Eemeren to be published). ${ }^{21}$ Such an argumentative pattern is characterized by a constellation of argumentative moves in which, in order to deal with a particular kind of difference of opinion, in defence of a particular type of standpoint a particular argument scheme or combination of argument schemes is used in a particular kind of argumentation structure. ${ }^{22}$ Next to relatively simple, "basic" argumentative patterns, covering only the first level of defence of a standpoint by the main argument or main arguments, in analysing argumentative practices more elaborated argumentative patterns can be distinguished, covering also further levels of defence and having varying degrees of complexity. ${ }^{23}$

\footnotetext{
18 Then it is first argued by means of symptomatic argumentation that dealing with a case in a certain way is justified because it is covered by a certain rule, and next by analogy argumentation that the case is similar to other cases to which the rule applies. Whether the symptomatic argumentation is supported by analogy argumentation or by some other type of argumentation depends on the kind of problem that needs to be solved. If a decision is to be made that requires a judge to make an exception to a general rule, pragmatic argumentation can be instrumental.

19 Then it is argued by means of the pragmatic subtype of causal argumentation that a measure should be taken because it will lead to a result the acceptability of which is beyond any doubt. If the acceptability needs to be motivated all the same, this can most simply be done by means of "symptomatic" argumentation. However, when such support is necessary, the argumentation loses its pragmatic force of straightforward effectiveness.

${ }^{20}$ Then it is argued by means of a certain subtype of causal argumentation that a thesis should be accepted because it is based on an established causal relationship.

${ }^{21}$ The occurrence an argumentative pattern can be explained by taking account of the institutional point and the institutional preconditions for strategic maneuvering in the (cluster of) communicative activity type(s) concerned in combination with the critical questions pertaining to the argument schemes that are used and the way in which the responses to these critical questions are supposed to hang together.

${ }^{22}$ The argumentative patterns that can be observed in argumentative discourse can be viewed as empirical analogues of the patterns of analytically relevant moves in a critical discussion that are on theoretical grounds distinguished in dialectical profiles. For the notion of a dialectical profile see van Eemeren (2010, pp. 98-100).

${ }^{23}$ The term level of defense refers to the distinction between the defense of a main standpoint (first level), the defense of (a reason serving as) a substandpoint (second level), the defense of (a reason for a reason serving as) a subsubstandpoint (third level), etc. (van Eemeren and Grootendorst 1992, Chapter 7).
} 
Although some argumentative patterns occurring in argumentative reality may well be incidental, certain argumentative patterns can be typical of the way in which argumentative discourse is generally conducted in a specific communicative activity type or cluster of communicative activity types. This is in principle the case when the argumentative pattern concerned is immediately connected with the institutional preconditions for strategic maneuvering pertaining to the communicative activity type that is examined. Such "prototypical" argumentative patterns, whose occurrence can be explained by the institutional preconditions prevailing in the communicative activity type in which they occur (van Eemeren and Garssen 2014), are of particular interest to pragma-dialectical researchers focusing on determining the context-dependency of argumentative discourse. ${ }^{24}$ These prototypical argumentative patterns result from the use of modes of strategic maneuvering that are preeminently instrumental in reaching the institutional point of a communicative activity type in accordance with its institutional preconditions while the specific critical questions pertinent in view of the institutional conventions of the communicative activity type are responded to. ${ }^{25}$

Pragma-dialectical research into strategic maneuvering is currently aimed at identifying the various prototypical argumentative patterns coming about as a consequence of the institutional preconditions for strategic maneuvering applying to the various kinds of argumentative practices in the legal, political, medical, and academic domain. ${ }^{26}$ In disclosing through qualitative empirical research the prototypical argumentative patterns which are functional in certain domains of argumentative reality, we make use of the various theoretical instruments developed in pragma-dialectics, such as the typologies of differences of opinions (single or multiple mixed or non-mixed), of standpoints (descriptive, evaluative, prescriptive), of argument schemes (causal, comparison, symptomatic), and of argumentation structures (single, multiple, coordinative, subordinative) (van Eemeren and Grootendorst 1992). The argumentative patterns manifesting themselves in the discourse in specific constellations of argumentative moves are described in terms of the categories and subcategories distinguished in these typologies.

\footnotetext{
${ }^{24}$ In speaking of a prototypical argumentative pattern I refer to a pattern that is characteristic of the communicative activity type in which it occurs because it is pre-eminently instrumental in realizing the institutional point of the communicative activity type. It stands to reason that it may be expected that in practice such an instrumental argumentative pattern will indeed be found in specimens of the communicative activity type. However, being prototypical does not necessarily mean that the pattern occurs frequently in this communicative activity type, let alone that it will always be present. If one thinks that the term prototypical is too strongly connected with absolute or relative frequency, it can be replaced by the term characteristic or some other term that does not carry this quantitative connotation.

25 The underlying assumption is that in principle protagonists may be supposed to aim for making the strongest case in the macro-context concerned by trying to advance a combination of reasons that will satisfy the antagonist through leaving no critical doubts unanswered, using the argument schemes they consider most effective in the situation at hand and advancing all multiple, coordinative and subordinative argumentation necessary to respond to the critical reactions the antagonist may be expected to come up with.

${ }^{26}$ Identifying prototypical argumentative patterns makes clear what kind of evaluation is required in assessing the argumentative discourse concerned and what exactly this evaluation involves. In addition, prototypical argumentative patterns can be helpful in teaching arguers how to conduct certain argumentative practices.
} 
In the qualitative empirical research concerning prototypical argumentative patterns I am currently carrying out together with Andone, Feteris, Garssen, Snoeck Henkemans and Wagemans, prototypical argumentative patterns are identified that are functional in specific communicative activity types in the political, legal, medical and academic domain. With the help of our analysis of the institutional preconditions pertaining to the various communicative activity types concerned we make clear why these argumentative patterns occur and how they occur. It is worth noting that in practice there may be various argumentative patterns that are prototypical of a particular communicative activity type or cluster of communicative activity types.

In actual argumentative practices, some prototypical argumentative patterns may occur more frequently than others and in specific (clusters of) communicative activity types or specific kinds of instantiations of a specific communicative activity type certain prototypical argumentative patterns may even be dominant in a quantitative sense. To investigate this quantitative dimension of argumentative patterns, the qualitative research we are carrying out will in the near future be followed by empirical research of representative corpuses of argumentative discourses in which the frequencies of occurrence of the various prototypical argumentative patterns are determined. In addition, comparisons of frequencies will be made between the various communicative activity types and communicative domains. In this way we will be able to establish which argumentative patterns that are prototypical of a certain communicative activity type or cluster of communicative activity types may be regarded as stereotypical in an absolute or relative sense. ${ }^{27}$

Systematically documenting the institutional diversification of argumentative practices in this way will provide empirically-based insight in the proliferation of argumentative reality. It will also pave the way for a more thorough account of the relationship between context-independency and context-dependency in argumentative discourse than has been provided by earlier studies in argumentation theory (e.g., Toulmin 2003). Because these issues are so fundamental and the way in which they should be approached has been a matter of continual debate, we expect that the insights gained from our research will be of vital significance to argumentation theory as a discipline.

\section{Argumentative Patterns with Pragmatic Argumentation as Main Argument}

Let us now turn to the specific theme of this special issue: argumentative patterns with pragmatic argumentation as a main argument. According to the pragmadialectical approach, argument (sub)schemes are to be distinguished from each

\footnotetext{
27 Thus I have made a terminological distinction between prototypical argumentative patterns characteristically used in realizing the institutional point of a certain communicative activity type and stereotypical argumentative patterns, which are not only prototypical but also occur frequently in the communicative activity type concerned. Generally, prototypical argumentative patterns can be brought to light by means of qualitative empirical research; stereotypical argumentative patterns can only be detected by means of quantitative research.
} 
other when, due to the critical questions pertinent to the argument (sub)scheme, they initiate a dialectical route in argumentative discourse that is different from the dialectical routes initiated by other (sub)schemes. Pragmatic argumentation is a subtype of causal argumentation because the pertinent critical questions are in some sense specifications of the critical questions pertinent to the general argument scheme of causal argumentation.

In pragmatic argumentation the standpoint that an action should be carried out (or should not be carried out) is defended by pointing out that the result of carrying out this action is desirable (or that the result of carrying out this action is undesirable). The "positive" variant of pragmatic argumentation defends a positive standpoint ("Action X should be carried out"), the "negative" variant defends a negative standpoint ("Action X should not be carried out"). The pragma-dialectical definition of the argument scheme of pragmatic argumentation in its positive version is as follows:

1 Standpoint Action $\mathrm{X}$ should be carried out

1.1 Because Action $\mathrm{X}$ will lead to positive result $\mathrm{Y}$

(1.1') And (Actions of type $X$ [such as $X]$ that lead to positive results of type $Y$ [such as $\mathrm{Y}]$ must be carried out)

Argumentation that is pragmatic is to be evaluated in accordance with the critical questions pertinent to the specification of the argument scheme of causal argumentation in this subscheme. This results in the following critical questions:

(a) Do actions of type $X$ lead to results of type $Y$ ?

(b) Is result $\mathrm{Y}$ really positive (i.e., desirable)/negative (i.e., undesirable)?

(c) Does action $\mathrm{X}$ not have any major negative (i.e., undesirable)/positive (i.e., desirable) side-effects?

As in other cases, the way in which these critical questions are implemented depends on the context of the communicative activity type in which the pragmatic argumentation concerned is used. If, when pragmatic argumentation has been advanced, certain critical questions are anticipated or responded to in the discourse, more complex argumentation will come into being, with a more complicated argumentation structure.

If in a certain argumentative practice the circumstances in which pragmatic argumentation occurs call for it, the list of critical questions must sometimes be expanded. As a sequel to question (a), for instance, the question can then be asked whether result $\mathrm{Y}$ could not be achieved more easily or more economically by other actions. As a sequel to question (b), the question can be asked whether another result (of type $Z$ ) would not be even more positive (i.e., more desirable) than results of type $Y$, such as Y. As a sequel to question (c), the question can be asked whether the negative (i.e., undesirable) side-effects can be prevented or suppressed, etc.

Depending on the exigencies of the macro-context, in the various kinds of argumentative practices the critical questions (a), (b) and (c) may be asked and responded to- - or anticipated and responded to. This does not mean, however, that all these critical questions will always be dealt with. In some cases it will be 
unnecessary to deal with a certain critical question because it is already clear that there is mutual agreement about the answer. It may also be the case that a particular critical question is not explicitly dealt with-or is explicitly dealt with-for rhetorical reasons of effectiveness. The same might apply to the critical questions added to the list because of the need for expansions motivated by the circumstances in which the argumentation occurs. In all cases, when they are implemented in a particular activity type the general critical questions need to be specified, amended and supplemented in accordance with the institutional requirements of the macrocontext.

It is a distinctive feature of pragmatic argumentation that it can only be instrumental in offering conclusive support of a prescriptive standpoint if, in the case of a positive standpoint, the positive character (i.e., desirability) of the result that is aimed for is clearly beyond doubt (or, in the case of a negative standpoint, the negative character, i.e., undesirability). In a political macro-context, for instance, the positive character of the result that is, according to the standpoint, to be achieved is often evident. Who would, for instance, object to the proposal of a policy measure leading to higher employment rates? If, for some reason or other, to some or all of the addressees the desirability of the result is not so obvious, this desirability needs to be motivated. However, when the desirability of the action that is proposed is no longer beyond doubt, the argument loses its pragmatic force.

In the macro-contexts of the legal domain it is generally a necessary requirement that the desirability of the action that is proposed will be explicitly motivated. In the political domain it may happen that it is not the positive value of the result to be achieved by the action (i.e., its desirability) as such that is at issue, but the relative value of this result compared with another result, which could be achieved by taking another action. This can, for example, be the case when the actions concerned have different positions in the existing value hierarchy or when the parties involved in the discussion favour different value hierarchies. The latter occurs, for instance, when for the protagonist fighting unemployment is the main problem while the audience (or a relevant part of the audience) considers putting an end to the budget deficit more important. ${ }^{28}$

Because of their relevance to the acceptance of the argumentation, the critical questions pertaining to pragmatic argumentation are likely to be anticipated in the discourse. This applies, of course, in the first place to the critical questions (in their specific contextual implementation) that are most pertinent in the institutional context in which the discourse takes place. In argumentative discourse taking place in communicative activity types in domains in which pragmatic argumentation is pre-eminently called for, such as the political domain and the legal domain, such anticipation of pertinent critical questions is likely to be expected. Due to the need to satisfy the institutional preconditions and to respond to the critical questions that are to be anticipated, the prototypical argumentative patterns coming into being in these domains may involve a combination of pragmatic argumentation with other

\footnotetext{
28 This may in the cases concerned lead to an amendment of the first critical question going with pragmatic argumentation so that is made relative to achieving some other result: "Is the result Y' really more positive, i.e., more desirable, than positive result Z', so that actions are preferable that lead to achieving the latter?".
} 
types of (coordinatively or subordinatively linked) argumentation. As a consequence, rather than being single and pragmatic in toto, the argumentation structure then becomes complex and the pragmatic argumentation is included in a more elaborate argumentative pattern.

Let us turn to the communicative activity type of a general parliamentary debate in the European parliament for an example. In their study 'In varietate concordia', van Eemeren and Garssen (2010) have shown that in such a debate pragmatic argumentation in support of a prescriptive standpoint is prototypically supported by means of (symptomatic) argumentation by example, by means of (symptomatic) authority argumentation or by means of descriptive analogy argumentation. According to their observations, it depends on the nature of the causal claim involved in pragmatic argumentation whether argumentation by example or analogy argumentation will be used in its support. If the causal claim is general, it needs to be defended by argumentation by example. Singular causal claims on the other hand can be defended by means of analogy argumentation. As a case in point, van Eemeren and Garssen mention the defence of the claim that the United States should adopt a policy of gun control defended by the pragmatic argumentation that this policy leads to a safer social environment. This defence can be readily supported by means of descriptive analogy argumentation in which the situation in the United States is compared to the situation in Canada, where gun control proves to lead to fewer casualties. The causal claim is in this case a specific one, referring only to the United States. Had the causal claim been general, as in "Gun control generally leads to fewer casualties", instead of analogy argumentation, argumentation by example would have been needed.

The study of other communicative activity types in other domains makes clear that pragmatic argumentation can also be defended by still other types of argumentation. In health communication in the medical domain, for instance, pragmatic argumentation can be supplemented with other pragmatic arguments. These other pragmatic arguments may concern other consequences that will occur. Alternatively, pragmatic argumentation can be supplemented by symptomatic argumentation concerning the positive or negative qualities of a drug that is discussed. In the latter case, the argument in which the positive or negative qualities are mentioned is in its turn prototypically supported by means of other symptomatic argumentation, such as a argumentation from authority referring to experience expertise.

\section{Argumentative Patterns Containing Pragmatic Argumentation}

The contributions to this issue share a pragma-dialectical perspective on argumentative discourse and are all based on the theoretical framework I have just explained. In all of them prototypical argumentative patterns are examined in which pragmatic argumentation plays a vital role. In all cases, this pragmatic argumentation is embedded in prototypical argumentative patterns that depend on institutional preconditions applying to specific communicative activity types or clusters of communicative activity types. The argumentative patterns that are discussed are 
prototypical of certain communicative activity types belonging to the political domain, the legal domain, the medical domain, and the academic domain.

The aim of Bart Garssen's paper, 'Problem-solving argumentative patterns in plenary debates of the European Parliament', is to describe the way in which argumentative patterns come into being in plenary debates over legislative issues. Garssen shows that such argumentative patterns depend for the most part on the problem-solving argumentation that the "rapporteur" of the parliamentary committee report regarding a certain issue has put forward in the opening speech. Starting from the observation that the argumentation that is advanced can be pragmatic problem-solving argumentation or complex problem-solving argumentation, Garssen examines the most prominent prototypical argumentative patterns in the contributions of the Members of parliament to the plenary debate. His research is based on an inventory of the arguments that can be used to support or attack the initial problem-solving argumentation put forward by the rapporteur.

In 'Argumentative patterns in the political domain', Corina Andone concentrates on the case of European parliamentary committees of inquiry. She examines the argumentative patterns resulting from combining pragmatic argumentation in which a recommendation is made with arguments in which the majority is invoked. Andone focuses on argumentative patterns that can be found in inquiries into the activity of the Equitable Life Assurance Society by European parliamentary committees of inquiry. By incorporating legal and political insights about the activities of these parliamentary committees into a pragma-dialectical approach, she provides an analysis of the selected argumentative patterns that reveals which standpoints in the recommendations that are made are supported by which arguments and how these arguments relate to each other. In addition, Andone's analysis explains the argumentative choices that are made.

In 'Prototypical argumentative patterns in a legal context', Eveline Feteris addresses prototypical argumentative patterns in the context of legal justification in which pragmatic argumentation is used in hard cases. First, she discusses the function of pragmatic argumentation in the legal domain and its implementation in prototypical argumentative patterns. She explains the dialectical function of the various parts of the complex argumentation that is advanced by characterizing them as argumentative moves put forward in reaction to certain forms of critique. Then, on the basis of the famous Holy Trinity case, she shows the way in which the pragmatic argumentation used by the U.S. Supreme Court is incorporated in prototypical argumentative patterns that come into being in dealing with the institutional preconditions of the case.

In 'Argumentative patterns in over-the-counter medicine advertisements', Francisca Snoeck Henkemans discusses an argumentative pattern including pragmatic argumentation that is prototypical for the communicative practice of over-the-counter medicines advertisements in the domain of health communication. First, she identifies a basic argumentative pattern of this type of advertisement. Next, she presents an overview of various types of extensions of this basic pattern. Finally, she makes clear how the basic pattern and its extensions can be analysed as the result of strategic choices by the advertisers concerning the type of 
argumentation that is advanced, the argumentation structure and the presentation of the argumentation.

In 'Argumentative patterns in scientific explanations', Jean Wagemans claims that in the academic domain the practice of justifying scientific explanations generates argumentative patterns in which several types of argumentation may play a role. In order to describe these patterns, he explores the institutional conventions regarding scientific explanations as reflected in influential works on the philosophy of science. First, he describes a basic pattern for justifying scientific explanations. Then, he presents two types of extensions of this pattern, which he derives from philosophical accounts of requirements for the quality of explanations and the choice of the best explanation respectively. With regard to the latter extension, he make clears what role pragmatic argumentation plays in justifying the choice of a particular explanation.

Open Access This article is distributed under the terms of the Creative Commons Attribution 4.0 International License (http://creativecommons.org/licenses/by/4.0/), which permits unrestricted use, distribution, and reproduction in any medium, provided you give appropriate credit to the original author(s) and the source, provide a link to the Creative Commons license, and indicate if changes were made.

\section{References}

Andone, C. 2013. Argumentation in political interviews. Analyzing and evaluating responses to accusations of inconsistency. Amsterdam-Philadelphia: John Benjamins.

Fairclough, N. 1995. Critical discourse analysis. The critical study of language. London: Longman Group Limited.

Feteris, E.T. 2009. Strategic maneuvering in the justification of judicial decisions. In Examining argumentation in context: Fifteen studies on strategic maneuvering, ed. F.H. van Eemeren, 93-114. Amsterdam: John Benjamins.

Ihnen Jory, C. 2010. The analysis of pragmatic argumentation in law-making debates: Second reading of the terrorism bill in the British House of Commons. Controversia 7(1): 91-107.

Ihnen Jory, C. 2012. Analysing and evaluating pragmatic argumentation in lawmaking debates: Institutional constraints on pragmatic argumentation in the British parliament. Unpublished doctoral dissertation University of Amsterdam.

Labrie, N. 2012. Strategic maneuvering in treatment decision-making discussions. Two cases in point. Argumentation 26(2): 171-199.

Lewinski, M. 2010. Internet political discussion forums as an argumentative activity type. A pragmadialectical analysis of online forms of strategic manoeuvring with critical reactions. Unpublished doctoral dissertation University of Amsterdam.

Mohammed, D. 2009. "The honourable gentleman should make up his mind”. Strategic manoeuvring with accusations of inconsistency in Prime Minister's Question Time. Unpublished doctoral dissertation University of Amsterdam.

Pilgram, R. 2015. A doctor's argument by authority. An analytical and empirical study of strategic manoeuvring in medical consultation. Unpublished doctoral dissertation University of Amsterdam.

Plug, H.J. 2010. Ad-hominem arguments in Dutch and European parliamentary debates: Strategic manoeuvring in an institutional context. In Discourse and metadiscourse in parliamentary debates, ed. C. Ilie, 305-328. Amsterdam: John Benjamins.

Plug, H.J. 2011. Parrying ad-hominem arguments in parliamentary debates. In Proceedings of the 7th conference of the International Society for the Study of Argumentation, ed. F.H. van Eemeren, B.J. Garssen, D. Godden and G. Mitchell, ch. 138, 1570-1578. Amsterdam: Rozenberg/Sic Sat. CD-rom.

Snoeck Henkemans, A.F. 2011. Shared medical decision-making: Strategic maneuvering by doctors in the presentation of their treatment preferences to patients. In Proceedings of the 7th conference of 
the International Society for the Study of Argumentation, ed. F.H. van Eemeren, B.J. Garssen, D. Godden and G. Mitchell, ch. 162, 1811-1818. Amsterdam: Rozenberg/Sic Sat. CD-rom.

Tindale, C.W. 2004. Rhetorical argumentation. Principles of theory and practice. Thousand Oaks: Sage. Tonnard, Y.M. 2011. Getting an issue on the table. A pragma-dialectical study of presentational choices in confrontational strategic maneuvering in Dutch parliamentary debate. Unpublished doctoral dissertation University of Amsterdam.

Toulmin, S.E. 2003. The uses of argument. Updated ed. Cambridge: Cambridge University Press (1st ed. 1958).

van Eemeren, F.H. 1986. Dialectical analysis as a normative reconstruction of argumentative discourse. Text 6(1): 1-16.

van Eemeren, F.H. 1987. Argumentation studies' five estates. In Argument and critical practices. Proceedings of the fifth SCA/AFA conference on argumentation, ed. J.W. Wenzel, 9-24. Annandale, VA: Speech Communication Association.

van Eemeren, F.H. 2002. Democracy and argumentation. Controversia 1(1): 69-84.

van Eemeren, F.H. 2010. Strategic maneuvering in argumentative discourse. Extending the pragmadialectical theory of argumentation. Amsterdam-Philadelphia: John Benjamins.

van Eemeren, F.H. 2013. In what sense do modern argumentation theories relate to Aristotle? The case of pragma-dialectics. Argumentation 27(1): 49-70.

van Eemeren, F.H. to be published. Pragmatic argumentation in stereotypical argumentative patterns. In Practical argumentation, ed. F.H. van Eemeren, E. Rigotti, A. Rocci, and D. Walton. AmsterdamPhiladelphia: John Benjamins.

van Eemeren, F.H., and B. Garssen. 2010. In varietate concordia-United in diversity: European parliamentary debate as an argumentative activity type. Controversia 7(1): 19-37.

van Eemeren, F.H., and B. Garssen. 2011. Exploiting the room for strategic maneuvering in argumentative discourse. Dealing with audience demand in the European Parliament. In Exploring argumentative contexts, ed. F.H. van Eemeren, and B. Garssen. Amsterdam-Philadelphia: John Benjamins.

van Eemeren, F.H., and B. Garssen. 2014. Argumentation by analogy in stereotypical argumentative patterns. In Systematic approaches to argument by analogy, ed. H. Jales Ribeiro, 41-56. Dordrecht: Springer.

van Eemeren, F.H., B. Garssen, E.C.W. Krabbe, A.F. Snoeck Henkemans, B. Verheij, and J.H.M. Wagemans. 2014. Handbook of argumentation theory. Dordrecht etc.: Springer.

van Eemeren, F.H., B. Garssen, and H.L.M. Meuffels. 2009. Fallacies and judgments of reasonableness. Empirical research concerning the pragma-dialectical discussion rules. Dordrecht: Springer.

van Eemeren, F.H., B. Garssen, and B. Meuffels. 2012a. Effectiveness through reasonableness. Preliminary steps to pragma-dialectical effectiveness research. Argumentation 26(1): 33-53.

van Eemeren, F.H., B. Garssen, and B. Meuffels. 2012b. The disguised abusive ad hominem empirically investigated. Strategic maneuvering with direct personal attacks. Thinking \& Reasoning 18(3): 344-364.

van Eemeren, F.H., and R. Grootendorst. 1984. Speech acts in argumentative discussions. A theoretical model for the analysis of discussions directed towards solving conflicts of opinion. Berlin: de Gruyter.

van Eemeren, F.H., and R. Grootendorst. 1992. Argumentation, communication, and fallacies. A pragmadialectical perspective. Hillsdale, NJ: Lawrence Erlbaum.

van Eemeren, F.H., and R. Grootendorst. 1994. Rationale for a pragma-dialectical perspective. In Studies in pragma-dialectics, ed. F.H. van Eemeren, and R. Grootendorst, 11-28. Amsterdam: Sic Sat.

van Eemeren, F.H., and R. Grootendorst. 2004. A systematic theory of argumentation: The pragmadialectical approach. Cambridge: Cambridge University Press.

van Eemeren, F.H., R. Grootendorst, S. Jackson, and S. Jacobs. 1993. Reconstructing argumentative discourse. Tuscaloosa, AL: University of Alabama Press.

van Eemeren, F.H., R. Grootendorst, and B. Meuffels. 1984. Het identificeren van enkelvoudige argumentatie [Identifying single argumentation]. Tijdschrift voor Taalbeheersing 6(4): 297-310.

van Eemeren, F.H., R. Grootendorst, and B. Meuffels. 1989. The skill of identifying argumentation. Journal of the American Forensic Association 25(4): 239-245.

van Eemeren, F.H., and P. Houtlosser. 2002. Strategic maneuvering: Maintaining a delicate balance. In Dialectic and rhetoric: The warp and woof of argumentation analysis, ed. F.H. van Eemeren, and P. Houtlosser, 131-159. Dordrecht: Kluwer Academic. 
van Eemeren, F.H., and P. Houtlosser. 2007. Seizing the occasion. Parameters for analysing ways of strategic manoeuvring. In Proceedings of the sixth conference of the International Society for the Study of Argumentation, ed. F.H. van Eemeren, J.A. Blair, C.A. Willard and B. Garssen, 375-380. Amsterdam: Sic Sat.

van Eemeren, F.H., P. Houtlosser, and A.F. Snoeck Henkemans. 2007. Argumentative indicators in discourse. A pragma-dialectical study. Dordrecht: Springer.

van Eemeren, F.H., B. Meuffels, and M. Verburg. 2000. The (un)reasonableness of the argumentum ad hominem. Language and Social Psychology 19(4): 416-435.

van Poppel, L. 2013. Getting the vaccine now will protect you in the future! A pragma-dialectical analysis of strategic maneuvering with pragmatic argumentation in health brochures. Unpublished doctoral dissertation University of Amsterdam.

Wagemans, J.H.M. 2011. The assessment of argumentation from expert opinion. Argumentation 25(3): 329-339.

Wenzel, J.W. 1990. Three perspectives on argument: Rhetoric, dialectic, logic. In Perspectives on argumentation: Essays in the honor of Wayne Brockriede, ed. R. Trapp, and J. Schuetz, 9-26. Prospect Heights, IL: Waveland.

Wierda, R. 2015. Strategic maneuvering with authority argumentation in direct-to-consumer medical advertisements. An analytical and experimental study into authority argumentation relying on experience expertise. Unpublished doctoral dissertation University of Amsterdam. 